\title{
PARA HOY Y PARA EL FUTURO: EL PROYECTO YO TAMBIÉN ESTUVE. CUANDO LA MEMORIA SE HACE PRESENTE.
}

\author{
FOR TODAY AND FOR THE FUTURE: THE PROJECT I WAS THERE TOO. WHEN MEMORY \\ BECOMES PRESENT
}

Ximena Orellana Román ${ }^{1}$

https://orcid.org/0000-0002-4206-1843 ximena.orellana@usach.cl

Mirtha Andrea Rivera Moreno ${ }^{2}$

https://orcid.org/0000-0003-0439-7407

alenguacast@gmail.com

Marcel Aranda Pericó ${ }^{3}$

https://orcid.org/0000-0002-7059-1796 marcelaranda@colegiopiamarta.cl

Marilyn Alejandra Lizama Muñoz 4

https://orcid.org/0000-0002-3178-8035 marilyn.lizama@gmail.com

Aceptado: 30/04/2021

Publicado online:30/05/2021

\begin{abstract}
RESUMEN
En el presente artículo se sistematiza el ejercicio de construcción de memoria del presente, como una práctica de subjetivación exitosa impulsada por el proyecto "Yo también estuve", que se centra - desde noviembre de 2019- en la recopilación, registro, resguardo y divulgación de relatos de la rebelión que se inicia en Chile en octubre de 2019. Dicha experiencia se promueve a la luz del deseo de reconocer la diversidad de voces de actores participantes en acciones de manifestación y protesta que traspasan las fronteras del ámbito privado para ocupar el espacio público. El ejercicio analítico que se consigna tiene como propósito dar cuenta del proceso realizado, los mecanismos de funcionamiento y colaboración incentivados por el proyecto; los métodos de análisis diseñados para la sistematización de la información $y$, asimismo, proponer algunos puntos de debate en torno a los procesos de subjetivación individual y colectivos, con el fin de dejar un rastro en la memoria y en la historia de estas vivencias de lucha.
\end{abstract}

Palabras clave: Memoria, procesos de subjetivación, relatos de vida, movilización social.

\footnotetext{
1 Universidad de Chile. Departamento de Educación en la Facultad de Humanidades.

2 Atica Ingeniería SpA Licenciada en Educación en Castellano. Máster Universitario en Tecnologías de la Información Comunicación Formación y Educación.

${ }^{3}$ Colegio Piamarta. Licenciado en Letras y Educación. Máster en Nuevas Tecnologías Aplicadas a la Educación.

4 Universidad De Chile, Instituto de la Comunicación e imagen. Periodista. Licenciada en Comunicación Social.
} 


\begin{abstract}
This article systematises the exercise of constructing memory of the present, as a successful practice of subjectivation promoted by the project "I was there too", which focuses - since November 2019 - on the collection, recording, safeguarding and dissemination of accounts of the rebellion that begins in Chile in October 2019. This experience is promoted in the light of the desire to recognise the diversity of voices of actors participating in actions of demonstration and protest that go beyond the boundaries of the private sphere to occupy the public space. The purpose of this analytical exercise is to give an account of the process carried out, the mechanisms of operation and collaboration encouraged by the project, the methods of analysis designed for the systematisation of the information, and also to propose some points for debate on the processes of individual and collective subjectivation, with the aim of leaving a trace in the memory and in the history of these experiences of struggle.
\end{abstract}

Keywords: Memory, processes of subjectivation, life stories, social mobilisation.

\title{
INTRODUCCIÓN
}

En el marco de la rebelión de octubre del 2019 en Chile, un número muy importante de la población chilena, en diversas ciudades del país, se integra al conjunto de movilizaciones, participando de diversas expresiones de protesta, sumándose a cacerolazos, marchas, barricadas, asambleas populares y territoriales, copamiento de calles y el espacio público. Las demandas que el movimiento levanta el 18 de octubre, comienzan a representar al conjunto de la sociedad: las consecuencias de la desigualdad, la pésima distribución de las riquezas, las denuncias del poder estudiantil monopólico, un sistema de salud insuficiente, pensiones que ofrece únicamente precariedad a adultos mayores, una educación que excluye entre ricos y pobres, etc.

Así, logran unificarse en el conjunto, las demandas que apuntan a todas aquellas medidas implementadas desde la junta militar facista hasta hoy.

Algunos análisis sociológicos proponen que este proceso explosivo de movilizaciones y expresiones de lucha representa un momento donde se producen transformaciones subjetivas, en el que se comienzan a romper las denominadas "subjetividades dominantes del capitalismo contemporáneo" y/o subjetividades neoliberales chilenas (Fardella y Soto, 2019: Araujo, 2019). Estas subjetividades que se trizan y resquebrajan se habían configurado - por estos últimos 30 años al menos - bajo conceptos de autorrealización, basados en el esfuerzo individual y que contenía además un estímulo o premio que significaba la posibilidad de alcanzar el goce del consumo.

La puesta en escena de este hastío individual sería entonces una oportunidad para poner en colectivo la necesidad de conversar, contar los hechos, relatar lo vivido y hacerse parte de una u otra forma de la historia. Las redes sociales se inundan de denuncias de abuso policial como militar. En paralelo y espontáneamente, surgen relatos e historias que marcan las diferentes visiones frente al contexto que dio origen a la indignación que moviliza de diversas maneras a la población chilena.

A partir de este deseo de compartir lo ocurrido surgen numerosos proyectos de rescate -lo que llamaremos en este artículo memoria presente-, vivenciado por una diversidad de personas, actores o testigos de la revuelta, apuntando al no olvido, exigiendo un lugar en el espacio de difusión y la posibilidad de ser parte de la historia -una historia que les ha sido negada- como señala Wieviorka (2012). Este rescate ha sido impulsado por diversos grupos de personas y/o agrupaciones, algunas vinculadas a alguna institución, otras desde la prensa alternativa, pero todas con el interés de que dichos relatos puedan constituir la historia popular chilena.

Entre los ejercicios de construcción de memoria presente, a través de relatos en primera persona, se pueden enumerar varios proyectos paralelos y con énfasis diferentes, como es el caso de: 
Añañuca Memoria ${ }^{5}$, Yo también estuve ${ }^{6}$, Primera Línea Prensa, la iniciativa \#relatosdelarevuelta Revolución en letras ${ }^{8}$, Proyecto AMA (Archivo de memoria Audiovisual) ${ }^{9}$ y Memoria Dibujada ${ }^{10}$.

Este artículo se enfocará en dichas prácticas de memoria presente, vinculando este deseo por relatar y compartir las vivencias que han surgido a partir de las protestas de octubre de 2019, con un proceso de subjetivación exitoso, de acuerdo con los planteamientos propuestos por Wieviorka, quien además releva la importancia de las redes sociales para la construcción de estos espacios de subjetivación, tal como lo propone en una entrevista en su paso por Chile en mayo de 2018:

“Las redes sociales no tienen el mismo nivel de comunicación que de acción. Por ello, los movimientos sociales más importantes actualmente son los que combinan al mismo tiempo redes sociales y capacidad de conocerse físicamente. Como el movimiento antiarmas de los jóvenes estadounidenses o el movimiento feminista." ${ }^{11}$

Es así que estas iniciativas digitales se fundan en la comunicación, en este hilo que vincula las vivencias personales con diferentes espacios y contextos de protesta.

\section{Figura 1}

Valentina Mora@ayewkiawun_(Instagram)

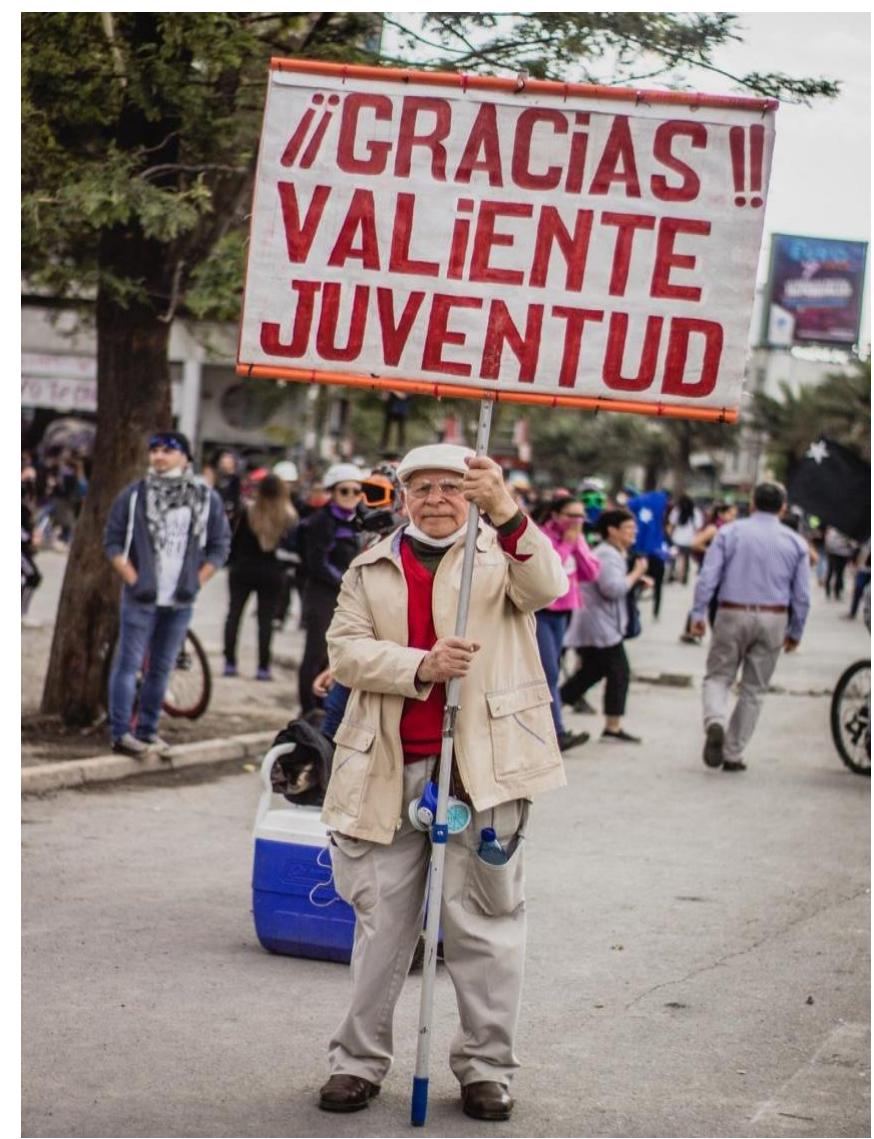

\footnotetext{
5 Proyecto Organización feminista que busca recuperar y visibilizar las memorias de mujeres, que genera una sección de fanzines de relatos de lucha, https://cutt.ly/rbh3ilw

${ }_{6}^{6}$ Proyecto levantado junto a otros/as profesionales de la educación, las comunicaciones (autores de este artículo) y que se propuso recopilar relatos de la rebelión popular en Chile contados en primera persona y que se asocia a fotógraf@s independientes para poner fondo con imagen a esas historias de la rebelión popular en Chile, ha publicado desde Noviembre de 2019 más de 200 relatos, https://cutt.ly/Xbh3pB0

7 Un ejemplo de estos es posible de encontrar en https://bit.ly/3elh4H9

${ }^{8}$ Se proponen contar al mundo la realidad:https://cutt.ly/1bh3gal

${ }^{9}$ Desarrollado por un equipo de periodistas asociado a recoger las historias de las personas víctimas de la violencia policial y militar en Chile, desde octubre de 2019

${ }^{10}$ Es el trabajo de una dibujante que a partir de relatos que las personas le envían produce dibujos de las situaciones que le propone la gente https://cutt.ly/Lbh3hLy ${ }^{11}$ Michel Wieviorka, sociólogo francés: "Los jóvenes de hoy son más pesimistas que los del Mayo del 68", https://cutt.ly/nbh3tXG, Diario La Tercera, mayo de 2018
} 
El presente artículo se basa en el trabajo independiente que se lleva a cabo desde principios de noviembre de 2019 en Chile. Se trata del proyecto de recopilación de relatos de la rebelión popular chilena llamado "Yo también estuve", que surge como iniciativa de un equipo de profesores y profesoras de Historia y Lenguaje ${ }^{12}$, dos periodistas y cuatro profesionales dedicados a la traducción, quienes suman sus fuerzas para implementar un ejercicio documental, de recopilación y difusión de relatos de la rebelión chilena a través de las redes.

La motivación que dio origen a "Yo también Estuve" fue el deseo de recoger las voces que estaban viendo o siendo partícipes de diferentes expresiones de protesta desde el 18 de octubre en Chile. El foco principal fue puesto en los relatos vivenciales de la rebelión popular, escritos en primera persona, centrando especial atención en acciones de resguardo y difusión de la memoria.

"Yo también Estuve" comenzó su funcionamiento en redes sociales, asociándose con la red de información y medios independientes que se gestó al margen de los medios de prensa oficial. Al pasar los días, se logra establecer lazos con organizaciones de distinto tipo, colectivos, asambleas barriales y territoriales; además de un conjunto de activistas y participantes de las diversas manifestaciones.

En paralelo, se fue urdiendo un trabajo colaborativo con fotógrafos y fotógrafas independientes que retratan las luchas en las calles. Estos y estas profesionales ofrecen la posibilidad de utilizar sus fotografías con el objeto de dar contexto a las situaciones descritas por las y los participantes ${ }^{13}$.

Luego de casi un año de trabajo sistemático, la iniciativa lleva más de 200 relatos de personas que voluntariamente han entregado sus vivencias en forma escrita. Hoy el equipo se encuentra en proceso de difusión de un libro llamado "Voces en rebeldía. 100 relatos de la revuelta iniciada en octubre de 2019", editado a finales del 2020.

\section{Procesos de subjetivación en los relatos del octubre chileno}

Para ubicarse en los ejercicios y prácticas actuales de construcción de memoria, es relevante situar el análisis desde la comprensión del sujeto propuesta por Touraine (2016) quien plantea:

“El sujeto es más fuerte y más consciente de sí mismo cuando se defiende contra ataques que amenazan su autonomía y su capacidad de aprehender como sujeto integrado, o al menos luchando por serlo, para reconocerse y ser reconocido como tal." (p. 75)

A partir de ahí es posible comprender que un sujeto se encuentra en actividad en el contexto social en el que se desenvuelve. En estas interacciones con el medio existe la posibilidad de que se provoque la subjetivación y la desubjetivación.

La subjetivación está relacionada con el reconocerse a uno mismo/a como alguien que tiene derechos, una afirmación individual y que además contiene una idea de un reconocimiento de un yo en un espacio colectivo. En cambio, la desubjetivación se manifiesta - entre otras formas- en un conjunto de conductas de perversión y debilitamiento de la acción conjunta o colectiva.

La idea de memoria entonces opera fuertemente vinculada con la sujetivación, y de ahí la utilidad para analizar el fenómeno que se está exponiendo.

Aunque suene de perogrullo, es importante señalar en el caso chileno que quienes deciden sumarse de diversas maneras a las protestas de la rebelión popular apelan a un conjunto de principios universalistas, asociados a las numerosas contradicciones sociales, políticas y económicas (pensiones, salud, trabajo, educación, demandas de género, vivienda, etc.). Estas manifestaciones se vinculan a

\footnotetext{
${ }^{12}$ Conformado en su equipo de base por Mirtha Andrea Rivera Moreno, profesora de Castellano y Máster en Tecnologías en educación y formación; Marcel Aranda profesor de Lenguaje y Máster en Tecnologías aplicadas a la educación; Ximena Orellana Román, profesora de Historia y Geografía, Magíster en Educación con mención en Informática educativa y actualmente estudiante del Doctorado en Ciencias Sociales de la Universidad de Chile; Marilyn Lizama Muñoz, periodista, Licenciada en Comunicación Social y gestora cultural y la Periodista que trabaja con el equipo bajo el seudónimo Leonor Kimün.

${ }^{13} \mathrm{~A}$ la fecha han colaborado más de 50 fotógrafos y fotógrafas independientes quienes han puesto a disposición bases de fotografías realizadas en el marco de las protestas callejeras, para seleccionar desde ahí insumos necesarios para dar contexto y valor visual a la situación retratada por su narrador o narradora.
} 
una demanda decidora que se instala en el discurso habitual: "Hasta que la dignidad se haga costumbre" y que en su esencia deja de manifiesto un componente fundamental de la subjetivación.

Así Touraine (2016) postula que se instala en los sujetos la capacidad y el derecho de ser creadores y, a partir de esta, la posibilidad de transformación de la realidad. Este momento de creación y capacidad de transformación de cada cual es la que denomina subjetivación, la que se pone en ejercicio a partir de los actos asociados a las exigencias de libertad e igualdad.

Wieviorka (2012) es más específico y preciso cuando refiere el concepto de sujeto, señalando que la capacidad de ser actores se constituye a partir de la capacidad de reflexionar, de construir su existencia y dominar la experiencia que les toca vivir, pero advierte que, para que se logre este proceso de construcción, es relevante tener acceso a los recursos necesarios. Si se cumple la combinación de estos factores se producirá la realización del sujeto. En este marco, los procesos de subjetivación refieren entonces, a aquellos que operan transformando la conciencia de los actores, lo que les habilita a la toma de decisiones y el pasar a la acción.

En el siguiente ejemplo es posible observar cómo opera la transformación de un sujeto que construye su existencia y domina la experiencia que le toca vivir, un sujeto que se forma en la acción, pues decide tomar partido por enfrentarse a las fuerzas represivas que están presentes en la Plaza Dignidad. El caso corresponde a un relato anónimo que fue recopilado por el proyecto Yo también Estuve antes mencionado:

"Ese día llegué como cualquiera a plaza Dignidad" ${ }^{14}$. Había demasiados pacos ${ }^{15}$, tantos, que me hicieron dudar si encapucharme ${ }^{16}$ o no. Tenía miedo, había como 3 guanacos ${ }^{17}, 4$ o 5 zorrillos ${ }^{18}$ y más de 5 furgones de FFEE ${ }^{19}$. Dejé el miedo atrás y me puse mi capucha. Iba solo con mi suerte y nada más..."20.

Pero, ¿qué lo diferencia de un antisujeto y de un no sujeto? Para aclarar esta interrogante Wieviorka propone que los no sujetos corresponden a aquellos actores que no son responsables de lo que hacen, pues actúan por órdenes; mientras que los anti-sujetos son aquellas personas que conducen a la destrucción y la negación deliberada del prójimo.

El ejercicio común que se realiza en la prensa oficial es catalogar de antisujeto a un joven como el del relato citado. Si se pone atención a un nuevo punto de interés:

"Yo soy cada persona que no puede ir a marchar, soy cada persona que se queda callada asumiendo la derrota, soy cada persona que espera que esto cambie... Soy la voz de los que no tienen, y de los que la callan, soy el agua con bicarbonato que te alivia de una lacrimógena, soy la música en contra de las armas, soy la lucha de todos los chilenos, y seguiré luchando de esa forma hasta el final... Soy primera línea".

En esta voz hay un sentido de misión, de ser parte de un colectivo, que no se enfrenta haciendo uso de la violencia por puro gusto, no hay violencia por violencia.

En paralelo, es posible distinguir en los relatos que se comparten en los proyectos enunciados más arriba un conjunto diferenciado y diverso de procesos de subjetivación y que dan cuenta de las acciones, por medio de las cuales se van transformando la conciencia de los actores. En ellos hay un conjunto de decisiones y reflexiones que encaminan a la acción. Tal es el caso de este relato del 18 de noviembre de 2019, compartido por una mujer de unos 35 años: "Hoy, después de mucho tiempo voy

\footnotetext{
${ }^{14}$ Plaza Dignidad se refiere a la antigua Plaza Italia ubicada en la ciudad de Santiago de Chile. Durante el proceso de rebelión popular las personas que asisten a actividades de protesta cambian su nombre y la rebautizan como Plaza Dignidad. Esto, influenció a las personas que se manifiestan en el resto del país quienes comienzan a renombrar las plazas donde se organizan las concentraciones y marchas en varias ciudades del país. Así se multiplican las plazas dignidad en Antofagasta, Concepción, Puerto Montt entre otras.

${ }_{15}$ Pacos, se refiere a una forma coloquial y despectiva de nombrar a la policía en Chile.

${ }^{16}$ Encapucharse, refiere a colocarse una capucha en el rostro de manera de cubrir el rostro y proteger la identidad de la persona

${ }^{17}$ Guanaco, refiere al carro policial que lanza agua química para dispersar disturbios. En Chile se denomina guanaco haciendo alusión al animal del altiplano que escupe a las personas cuando se le acercan.

${ }^{18}$ Zorrillos, refieren a los carros policiales que lanzan gases.

${ }^{19}$ FFEE, Fuerzas Especiales de carabineros.

${ }^{20}$ Fuente, proyecto Yo también estuve, relato del 12 de Enero de 2020, Santiago, accesible por el siguiente enlace: https://cutt.ly/Rbh3z6l
} 
a una marcha masiva. Hoy se cumple un mes del despertar de Chile. Hoy, dejé a mi hijo pequeño en casa para poder marchar junto a quienes sigo reconociendo como mi pueblo...".

Sus palabras dan cuenta de que decide salir a la calle para fundirse con muchas personas iguales con las que se identifica y con quienes elabora acciones conjuntas: "...Ahí está! en la calle una vez más, dándonos lecciones de cómo construir vida en comunidad...". La voz representa la persona como actor/a, por lo tanto, pasa a formar parte de una acción colectiva, vinculando las vivencias propias y familiares a las injusticias de muchos y muchas:

"Hoy volví a estar donde debía, por mi mami que en dos años recibirá una pensión de miseria, por mi hijo y su derecho a una salud de calidad y garantizada, (...) Y por esta generación (...) porque no tenga que endeudarse media vida para estudiar y después cargar con la vejez de sus padres"21

El esfuerzo de este artículo se ha centrado en situar el ejercicio de construcción de memoria del presente como una práctica de subjetivación que se instala a partir de la necesidad o la intencionalidad de transformación de la realidad. Se concibe la memoria como un componente de la acción colectiva, un conjunto de reivindicaciones que demanda su reconocimiento y que contiene conexiones entre el pasado y el presente (Wieviorka, 2012), que releva la continuidad de un conjunto de desigualdades, discriminaciones, injusticias, todas ellas ancladas en los problemas estructurales de la sociedad que no se han resuelto.

En el artículo se utiliza el concepto de memoria del presente, precisamente aludiendo a la idea de carga memorial de la acción colectiva que contiene el conjunto de reivindicaciones que se se producen a partir de la rebelión iniciada en Chile en octubre de 2019 y al mismo tiempo se funde con la subjetividad de los actores. Esto es precisamente lo que expresan los narradores, participantes directos del proyecto "Yo también estuve", quienes de alguna manera demandan, a partir de sus subjetividades, exigir justicia y convertirse en parte protagónica de la historia de hoy.

El ejercicio analítico que se consigna entonces tiene como propósito dar cuenta del trabajo sistemático realizado, desde hace más de un año, para levantar y sostener este proyecto independiente, pero también proponer algunos puntos de debate en torno a los procesos de subjetivación individual y colectivos que se han desarrollado al alero del presente ejercicio de investigación, recopilación y registro de la memoria del hoy.

\section{METOdOLOGÍA}

El proyecto digital de recopilación de relatos e historias de lucha "Yo también estuve" surge como una iniciativa de un colectivo de profesionales de la educación, periodistas y traductores, que sienten la necesidad de contribuir al ejercicio de construcción de memoria activa luego del inicio de las intensas jornadas de protesta, después del 18 de octubre en Chile. Surge entonces a la luz del deseo de contribuir en el proceso de dejar registro de los hechos y sensaciones, desde la perspectiva propia de los actores, sin interpretaciones, ni análisis.

El mecanismo de recogida de los relatos se ha realizado de manera pública estableciendo canales de comunicación abierta con narradores y narradoras. Las personas escriben sus testimonios y los envían por correo, a través de un formulario de encuestas y/o por mensajería interna en las redes sociales. Es un ejercicio voluntario, individual y que se asocia a una fecha y un lugar determinado en la que ocurre el hecho o situación que se describe. Asimismo, se trabaja en la consigna dos cuestiones que van en paralelo. Por una parte, el reconocimiento de la autoría individual de la vivencia y, por otra, la protección de la fuente que permite no revelar la identidad de quien expone.

Estas dos cuestiones se han ido combinando de tal forma que ha ido en aumento el nivel de confianza como la participación de narradores y narradoras en la exposición de situaciones que

\footnotetext{
${ }^{21}$ Fuente, proyecto Yo también estuve, relato del 18 de Noviembre de 2019, Santiago, accesible por el siguiente enlace: https://cutt.ly/hbh3RHM
} 
representan experiencias de violencia del Estado, violaciones de los derechos humanos, deseos de rebelión o en otros casos situaciones más cotidianas relacionadas con la pérdida del miedo de las personas a hacerse parte activa del movimiento.

El método utilizado para el proceso de recopilación de relatos se asocia con el conocido sistema "bola de nieve o cadena", pues emergen nuevas historias o escritos de manera flexible y dinámica, que va ampliándose de manera regular a partir de la emergencia de participantes, la diversidad de perspectivas y a medida que el ejercicio de divulgación se multiplica a través de las redes sociales. Esto en la práctica ha permitido recopilar -al momento de sistematizar el presente artículo 200 escritos con diversidad de narradores y narradoras distribuidos en varias regiones de Chile.

La práctica de recopilación integra un principio de respeto hacia los escritos de quienes van compartiendo sus vivencias. A través de un equipo de editores y editoras de textos se realiza un proceso de edición de estilo. Sin alterar el contenido de los relatos, ni expresiones populares, ni formas de atribuir al género, trabajan en pulir estos relatos para los futuros lectores.

En el momento en que este proceso está terminado se realiza el ejercicio de traducción al inglés. Un equipo de traductores voluntarios trabaja con el objeto de llevar la historia y vivencias del Chile actual a personas de habla inglesa.

A continuación, se realiza la divulgación, a través de las redes sociales. En este espacio los relatos -que ya han sido enumerados, editados e identificados con el nombre de cada narrador o narradora, el lugar y la fecha de la situación descrita para situar a las y los lectores- se acompañan con una imagen representativa, que es recogida de una base de recursos gráficos propuestos por fotógrafos. De esta manera se enriquece gráficamente el relato.

Todo este proceso de trabajo con fuentes directas representa una perspectiva investigativa que se asocia con la historia oral, la búsqueda y producción de documentos personales, asociados al acercamiento a la forma en cómo los sujetos sociales dan cuenta de sus propias experiencias (Aceves, 2008). Se basa en el análisis documental orientado específicamente a la recogida de relatos de vida en forma escrita, producidos en primera persona.

En estos relatos no se borra la subjetividad producida por los sujetos, no se interviene con una estructura o entrevistas sólo se orienta a la descripción de hechos concretos, vinculados a un momento y lugar determinados. Esta perspectiva, se acerca a lo que se describe el campo de la sociología como enfoque biográfico (Bertaux, 1999).

En este sentido la perspectiva investigativa a la que se adhiere, se contextualiza en la recopilación de relatos de una diversidad de individuos que no presentan una identidad homogénea, sino que es posicional y estratégica (Güelman \& Borda, 2014), pues dependerá del momento en que el relato fue escrito, el nivel de participación de cada narrador o narradora, del lugar y del rol que cumple y, en este caso, en la situación descrita.

El acercamiento a los métodos biográficos en la práctica del proyecto "Yo también estuve", no tiene como único sentido la recolección de experiencias anecdóticas de la diversidad de fuentes trabajadas, más bien se orienta a la reconstrucción del contexto social que da origen a las situaciones vividas y que configura las perspectivas o esperanzas de cambio que encierran estas memorias del presente.

A la luz de estas perspectivas se realiza la organización de 169 relatos recopilados y publicados entre noviembre de 2019 y agosto de 2020, que representan los primeros diez meses de lucha que se verán reflejado en la edición de un libro, publicado por Ceibo Ediciones.

En esta publicación se propone una antología de 100 relatos de la rebelión chilena, donde se establecieron criterios de inclusión-exclusión para la selección de cada texto los que abordan la representatividad en las categorías acordadas por el equipo, el valor narrativo de cada testimonio y el nivel de acogida por parte de los y las lectoras en redes sociales. 


\section{RESULTADOS}

Un primer ejercicio analítico realizado con los datos recopilados en el período que se señala en el apartado anterior se realiza a la luz de la necesidad de organización de los relatos en categorías para continuar trabajando en diferentes perspectivas de análisis.

En primer lugar, el ejercicio se concentra en la organización, la inclusión y exclusión de los relatos para la publicación en formato libro, a partir del ordenamiento de los relatos en categorías que se proponen en la gráfica organizada a continuación. Se establece una definición para cada una de las categorías enunciadas, diferenciando entre ellas varios tipos, personas que cumplen ciertas funciones en la protesta o manifestaciones de cualquier tipo, lugares de enunciación de los relatos, roles en la sociedad, las que se operacionalizan a continuación.

\section{Figura 2}

Gráfica de elaboración propia

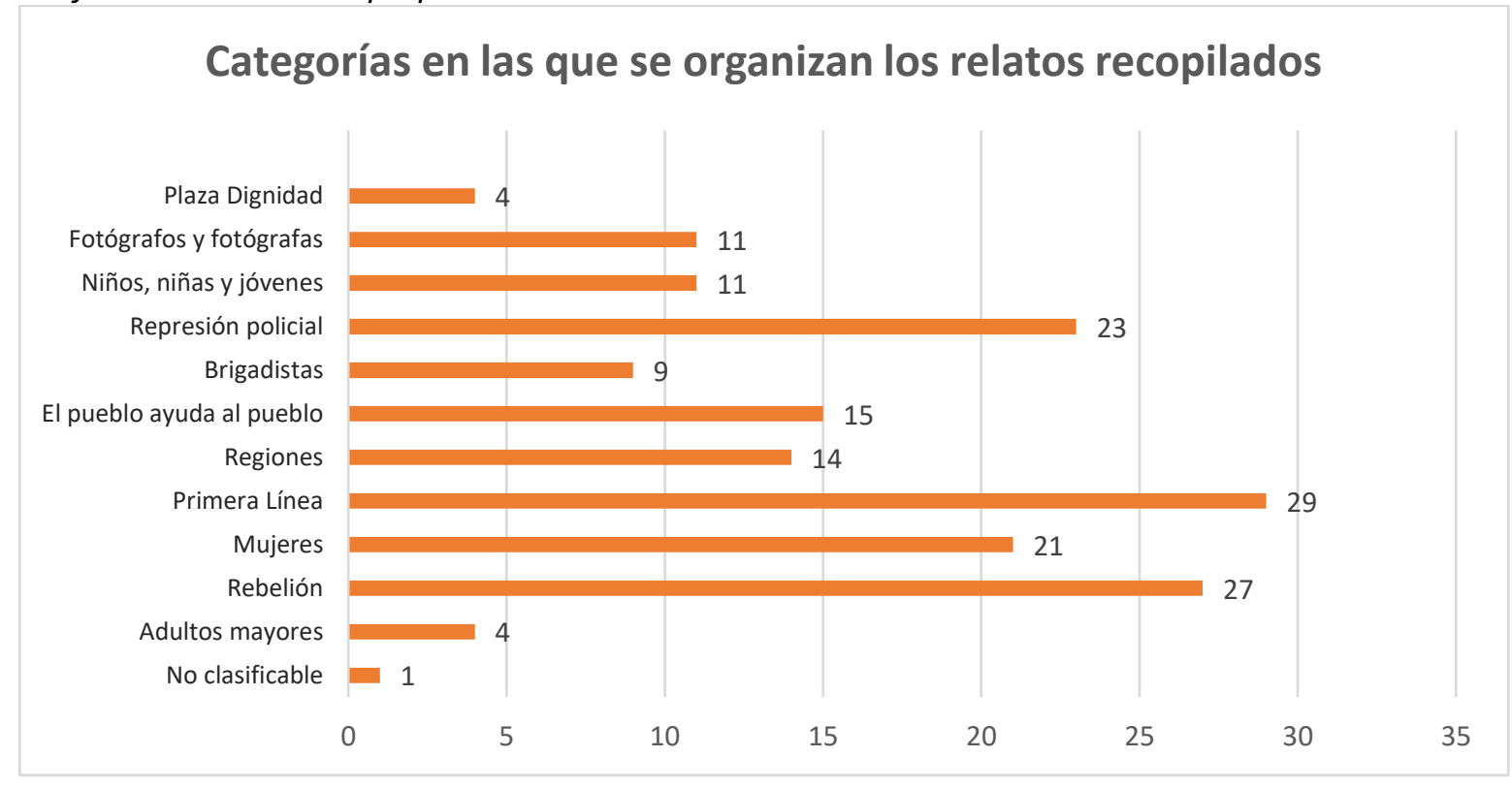

Primera línea: personas que se enfrentan a carabineros para permitir que los manifestantes se reúnan y protesten, asumen distintas funciones logísticas y estratégicas desde su posición de avanzada o como barrera y obstáculo, tienen distintas edades y proceden de diferentes sectores de la ciudad, hay relatos directamente contados por ellos, pero otros hablan acerca de su lucha

Brigadistas y salud (brigadistas): trabajadores y trabajadoras de la salud que atienden a las personas heridas y que se encuentran apostados en lugares estratégicos, cercanos a los focos de las protestas. Hay relatos en los que los y las brigadistas son atacados por carabineros y no se encuentran precisamente cumpliendo su función.

Regiones: distintas ciudades o pueblos en los que se observa la organización y la lucha de la gente en contextos propios, con su identidad, sus calles, sus espacios, su lenguaje y sus costumbres.

Género y mujer (mujeres): manifiestan la visión, la mirada de mujeres de diferentes edades y procedencias, ya sea como participantes activas en una situación, o como observadoras y testigos de una realidad, la conciencia feminista eleva la dignidad de su voz, los problemas de género, las opresiones del sistema y del modelo que llevan a que lo que hace la mujer lo hace con más esfuerzo, participar en el espacio público que antes ha sido castrado. 
Niños y jóvenes: aparecen niños niñas y adolescentes en situaciones de denuncia, toma de conciencia, se manifiestan experiencias escolares de lucha.

Abuelos: relatan o son parte de historias en las que están en las manifestaciones expresando el reconocimiento hacia los más jóvenes, a su propia lucha de otros tiempos, a la emoción de ver a un pueblo luchar por los ancianos y ancianas.

Rebelión: aquellos relatos que se fundan en la toma de decisión y de participación en forma individual o colectiva desde una sensación de rabia, ira e indignación.

Plaza Dignidad: la plaza dignidad como espacio simbólico para la protesta, pueden ser plazas en distintas ciudades.

El pueblo ayuda al pueblo (Solidaridad): las personas salen a ayudar a quienes luchan para sostenerlos, o la ayuda surge en el momento cuando las circunstancias les llevan a tomar una decisión de renuncia de sí mismos/as y de jugársela por las demás personas.

Fotógrafos y fotógrafas: cumpliendo su trabajo de denuncia y registro de situaciones a través de lo visual, presencian o son parte de situaciones que les sobrepasan y necesitan expresarlo también a través de una historia contada con palabras.

Represión policial: represión del Estado ejercida por los distintos organismos de seguridad y orden público.

Cada una de esas categorías representará un apartado del libro, que se renombrarán en función de un título de valor narrativo que invite a su lectura. A partir de este ejercicio de categorización, se realiza una segunda aproximación, que implicó una nueva lectura detallada de cada texto, con el objeto de desentrañar los conceptos de construcción de memoria del presente y su relación con los procesos de subjetivación que resultan un foco analítico principal de este trabajo.

\section{DISCUSIÓN}

Lo primero que se necesita relevar es que el proceso de investigación realizado se ha enfocado en la construcción sistemática de nuevas fuentes, a partir de la idea de integrar aquellas voces (Aceves Lozano, 1999) y personas que se consideran habilitadas a construirse como actores para referirse a la historia. Con este considerando inicial el proyecto de construcción de la base de datos de la memoria popular, que se inicia en octubre de 2019 , se constituye en un ejercicio que ha sido dinámico, flexible, y que progresivamente ha ido incluyendo más miradas, nuevas articulaciones con personas, organizaciones y una creciente masividad en tanto vive en diálogo constante con el conjunto de aquella diversidad de expresiones de lucha que se han desenvuelto en Chile en el último año y medio.

\section{Construcción de memoria en el presente, ¿un componente que aporta a los procesos de subjetivación?}

Para situar adecuadamente las prácticas de construcción de memoria que se han estado discutiendo en estas páginas es importante retomar uno de los primeros planteamientos que propone Wieviorka (2018) que refiere a la utilización de las redes sociales como un espacio de subjetivación. Dicha idea es desarrollada en profundidad por Castells (2012) descrita en el libro Redes de Indignación y Esperanza: los movimientos sociales en la era de internet. En él ejemplifica con los casos de Túnez y Egipto el rol que cumplen las redes sociales en la conexión de los movimientos sociales y establece que dichos espacios digitales son facilitadores para superar el temor impuesto por el poder. Al mismo tiempo señala que estos espacios resultan difíciles de controlar para los gobiernos y corporaciones.

Ha sido necesario recalcar la importancia de las redes sociales en el presente apartado, ya que precisamente el ejercicio de construcción de memoria - que se ha venido implementando- se vincula fuertemente con las redes sociales, y tal como se señala, no corresponde únicamente a una experiencia 
o proyecto de recopilación aislado, sino al menos con seis proyectos o iniciativas independientes que se han logrado pesquisar.

Además, si vinculamos lo anterior con la concepción de memoria propuesta por Wieviorka (2012) establece que es un elemento de acción cultural, histórica o moral, y que no necesariamente, se relaciona con una acción social -pensando en el término clásico de la acción emancipatoria- y se enfoca a partir de personas individuales quienes, tal como en el ejemplo que se detalla a continuación, irrumpen en el espacio público para poner en juego un cuestionamiento al relato que se construye a nivel oficial.

Para dar sentido al planteamiento anterior resulta de utilidad traer a colación un extracto del siguiente relato fechado el 21 de noviembre de 2019 y ocurre en el centro de Antofagasta:

"Era un día normal. Había paro nacional. Preparamos escudos e hicimos un comité de resguardo para defender a las familias, personas en situación de calle y todo aquel que se veía expuesto a la violencia de la calle. Todo marchaba bien, hasta que comenzó la represión (...) Fue tan impactante ver a mis compañeros arrollados por un sujeto que no sabía diferenciar. Nadie había saqueado su local. Él tomó la justicia por sus manos, sin medir las consecuencias...La alcaldesa de Antofagasta avaló su actuar, pero todos los que estuvimos ese día sabemos que nadie tocó su local"22.

Esta voz, que en este momento asume el tono de denunciante, participante y observador del trágico atropello, se opone al relato construido a nivel oficial, en este caso la alcaldesa de Antofagasta ${ }^{23}$ y decide compartirlo para dejar en alguna parte de la historia registro de estos hechos que podrían haber sido fatales.

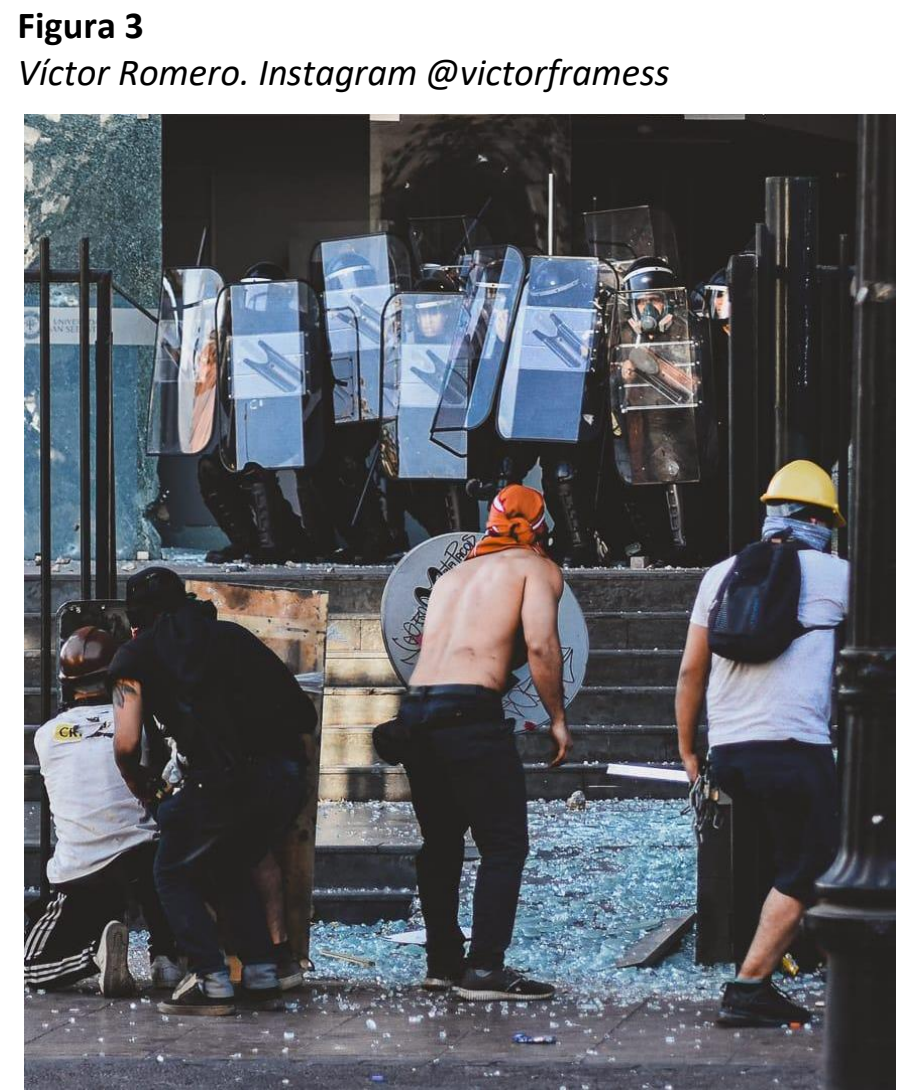

\footnotetext{
${ }^{22}$ Fuente, proyecto Yo también estuve, relato 129 del 21 de Noviembre de 2019 ocurrido en la ciudad de Antofagasta, accesible por el siguiente enlace: https://cutt.ly/Jbh3IrX

${ }^{23}$ El relato oficial de la alcaldesa de Antofagasta, Karen Rojo justificando la acción repudiada por el narrador se puede pesquisar en el siguiente archivo de prensa: https://cutt.ly/Tbh3Pvh
} 
Ha sido posible corroborar que el ejercicio de investigación y acción promovido por el proyecto "Yo también estuve" ha permitido desarrollar procesos de subjetivación exitosos, ya que se combinan el poder comunicativo de las redes sociales con la acción (Wierkova, 2018) con el deseo y demanda de reconocimiento de diversos actores/as sociales. Un conjunto numeroso de personas participantes apela a las contradicciones sociales, políticas y económicas a las que se ven expuestas, proponiendo una diversidad heterogénea de lugares de enunciación, a través de roles que cumplen en la sociedad, género y niveles de participación diferenciada en la protesta social.

El conjunto de voces recopiladas cree firmemente en la injusticia del olvido, lo que se puede vincular con otro de los elementos propuestos por Wieviorka quien refiere a la necesidad de reconocimiento de lo vivido, en tanto esto aportaría a la vida colectiva. Aunque esto, en la concepción del autor, se refiere específicamente a situaciones asociadas a violaciones de DDHH, se puede relacionar con las motivaciones que movilizan a las personas que han tomado la decisión de participar de proyectos como los que se vienen describiendo en el documento.

En este contexto, también es posible encontrar los relatos y vivencias de víctimas de violencia de las fuerzas de orden, de acciones de represión, pero también los hay de esperanza, de ira, de solidaridad bajo el lema "el pueblo ayuda al pueblo". Protesta espontánea y organizada, ampliando así la diversidad de formas en que se representan las memorias colectivas. De ahí deviene el concepto de carga memorial de la acción colectiva (Wieviorka, 2012) que representa la subjetividad de las personas, quienes exigen un espacio posible en la historia, pues se corresponde con un pasado que les pertenece y que afectó sus vidas. En paralelo también, dichos ejercicios de construcción de memoria son ejemplos evidentes de procesos de subjetivación exitosa.

La cuestión entonces será preguntarse, ¿cómo estos ejercicios de memoria toman lugar en el espacio público? En este caso un espacio público que dialoga con el digital, como su extensión casi natural, a través de las redes sociales. Allí es donde - cada vez con más naturalidad - se comparte, se toma el pulso de lo que pasa en la calle como respuesta y en rebeldía a la negación e invisibilización de sus voces en los medios de difusión oficial. Asimismo, la memoria producida por estos relatos se reafirma a sí misma, ayuda a reafirmar a otros y otras, pues construye la sensación de ser parte de la misma historia, del mismo pasado, sumándose a la gama de factores que un sujeto toma en cuenta para definir si actúa o no frente a determinada realidad.

Así como la prensa oficial no reconoce las posiciones y las voces de los “patipelados" ${ }^{24} y$ no les da validez, es necesario preguntarse ¿a qué campo corresponden estos relatos?, ¿cuál es la ciencia que estudia este sentir popular?, ¿será terreno exclusivo de la ciencia política?, ¿tiene algún lugar la historia? En este punto Wieviorka, establece que el papel de la memoria "...obliga a la historia a ubicarse dentro de la sociedad, la convoca a la transformación, le prohíbe pasar por alto la vida cotidiana" (p.11)

\section{CONCLUSIONES}

Los casos que se han revisado a través de estas páginas refieren a procesos de subjetivación exitosa y han sido parte fundamental en la construcción de lo que se ha denominado memoria presente, y refiere a la decisión de un conjunto de personas que en forma individual han decidido compartir sus voces, vivencias y experiencias de la rebelión popular chilena, traspasando el ámbito privado y ocupando el espacio público, por medio de las redes sociales, y compartiendo a la par con otra diversidad de voces individuales.

Continuamente es posible leer en la calle la siguiente leyenda: "las murallas son los diarios del pueblo". Esto porque los medios de difusión masiva se encuentran cooptados por intereses

${ }^{24}$ Patipelados, según la Real Academia de la Lengua (RAE) m. y f. coloq. Chile. Persona carente de toda clase de recursos. Se hace referencia a los que no tienen voz en la prensa oficial. https://dle.rae.es/patipelado 
económicos y por el orden público. En un símil, las redes sociales cumplen un rol flexible, accesible, masivo y se han convertido en el espacio de expresión de las ideas de rebelión que no tienen cabida en los canales formales y en los que no tienen oportunidad en tantos lectores o protagonistas verse representados y representadas en las historias de otros. Esta memoria presente que se construye en relación con procesos de un pasado inmediato y nos habla de sucesos que se están viviendo y que reclaman reconocimiento y un espacio en la historia.

Por otra parte, se ha configurado un interesante fenómeno: la decisión de entregar el relato, basado en principios de confianza, y al encontrar en estos proyectos un canal de expresión para hacerse parte de la historia. Por esto parece fundamental dejar instalada la interrogante que Wieviorka plantea ¿Cómo hacer que la historia no sea perezosa a estos testimonios?

\section{REFERENCIAS BIBLIOGRÁFICAS}

Aceves Lozano, J. (marzo de 1999). Un enfoque metodológico de las historias de vida. Revista Proposiciones, 29. Retrieved Octubre de 2020, from http://surcorporacion.cl/publicaciones/Revista_Proposiciones/PR-0029-001-3252.pdf

Anónimo. (2020). Relato \#140, 12 de Enero de 2020. Recuperado el 23 de julio de 2020, desde https://www.instagram.com/p/CA_t1TnppV9/

Anónimo. (2019). Relato \#24, 19 de Noviembre de 2019. Recuperado el 23 de julio de 2020, desde https://www.instagram.com/p/B5dl6P4F5lt

Anónimo. (2019). Relato \#24, 19 de Noviembre de 2019. Recuperado el 23 de julio de 2020, desde https://www.instagram.com/p/B5dl6P4F5lt

Bertaux, D. (1999). Enfoque biográfico: su validez metodológica, sus potencialidades. Proposiciones, 29, 1-23. https://www.academia.edu/download/55138254/bertaux.pdf

Castells, M. (2012). Redes de indignación y esperanza: los movimientos sociales en la era de Internet. Madrid: Editorial Alianza.

Febbro, E. (2020). Michel Wieviorka: "En este momento, el poder está desbordado". Página 12. Recuperado de https://www.pagina12.com.ar/263433-michel-wieviorka-en-este-momentoel-poder-esta-desbordado

Güelman, M., \& Borda, P. (2014). Narrativas y reflexividad: los efectos biográficos del enfoque biográfico Revista Latinoamericana de Metodología de las Ciencias Sociales 4. http://www.relmecs.fahce.unlp.edu.ar/

Serra Bachs, P. (2018). Michel Wieviorka, sociólogo francés: "Los jóvenes de hoy son más pesimistas que los del Mayo del 68". La Tercera. Recuperado de https://www.latercera.com/mundo/noticia/michel-wieviorka-sociologo-frances-los-joveneshoy-mas-pesimistas-los-del-mayo-del-68/162974/

Soto, Á. (2019). La revuelta de octubre: ¿Una crisis de la subjetividad neoliberal chilena?, entrevista a Kathya Araujo. El Mostrador. Recuperado de:

https://www.elmostrador.cl/destacado/2019/11/01/la-revuelta-de-octubre-una-crisis-de-lasubjetividad-neoliberal-chilena/

Soto, Á., \& Fardella, C. (2019). Del yo al nosotros: el emplazamiento colectivo a las subjetividades neoliberales. En K. Araujo, Hilos tensados: para leer el octubre chileno (1st ed., pp. 243- 270). Santiago de Chile: Editorial USACH. Recuperado de https://editorial.usach.cl/sites/default/files/HILOS\%20TENSADOS\%20WEB.pdf

Touraine, A. (2016) El fin de las sociedades. 1a ed. electrónica. Ciudad de México: Fondo de cultura económica.

Touraine, A. (2005) Un nuevo paradigma. Para comprender el mundo de hoy. Ciudad de México: Editorial Paidós.

Wieviorka, M. (2012). Du concept de sujet à celui de subjectivation/dé-subjectivation. Fondation Maison des sciences de l'homme. Recuperado de https://halshs.archives-ouvertes.fr/halshs00717835 